\title{
Assessment of Knowledge and Application of CBCT Among Dental Professionals - A Questionnaire Study
}

\author{
Reshma Ramachandran ${ }^{1 *}$ and Sushmini Hegde ${ }^{2}$ \\ ${ }^{1}$ Master of Dental Surgery, Department of Oral Medicine and Radiology, The Oxford \\ Dental College, India \\ ${ }^{2}$ Master of Dental Surgery, Reader - Department of Oral Medicine and Radiology, The \\ Oxford Dental College, India \\ *Corresponding Author: Reshma Ramachandran, Master of Dental Surgery, \\ Department of Oral Medicine and Radiology, The Oxford Dental College, India.
}

Received: January 18, 2021

Published: January 30, 2021

(C) All rights are reserved by Reshma

Ramachandran and Sushmini Hegde.

\begin{abstract}
Background: CBCT is an imaging technique which uses a cone shaped radiation that is focused on a 2D detector. It has been widely accepted in practice in radiology as well as academic and hospital settings. The present study is aimed to assess the knowledge and application on CBCT among dental professionals.

Materials and Methods: A validated questionnaire was distributed among 250 dental professionals.

Results: Most of the respondents were unsure about the radiation exposure of CBCT when compared to other types of imaging and all of them were willing for a CBCT hands on.

Conclusion: We concluded from our study that unfamiliarity with the use of CBCT among dental professionals due to insufficient curriculum and decreased practical exposure. So we recommend that by increasing the number of education programs, the knowledge on CBCT and its application should be increased to improve dental health care practice.
\end{abstract}

Keywords: CBCT; Imaging; Detector; Exposure; Radiation; Dentists; Knowledge of Dental Professionals

\section{Introduction}

Cone beam computed tomography (CBCT), sometimes referred to as cone beam volumetric imaging (CBVI). It is a three dimensional dental and maxillofacial imaging modality. The technology involves imaging a volume that allows either the entire maxillofacial skeleton or a restricted dento-alveolar region involving a few teeth to be imaged [1].

The use of CBCT was testified for the maxillofacial region imaging in 1988 by Mozzo., et al. and in 1999 by Arai., et al. Since then there is a rapid growth in cone beam technology and its maxillofacial application [2].
CBCT has been shown to be an excellent diagnostic modality for maxillofacial imaging as well as numerous applications in dentistry. The ability to provide a rapid scan and reduce the radiation dose in comparison with CT and the presence of interactive display modes offers maxillofacial imaging and multi-planar reformation images. These make them more useful tool at the work place of dental practice even though it is an extensively used modality. Most of the professionals have limited knowledge about CBCT. Hence the present study was to assess the knowledge on application of CBCT in dental professionals. 


\section{Materials and Methods}

A validated questionnaire survey with 15 questions was carried among 250 dental professionals, to assess their knowledge on application of CBCT. The study protocol was reviewed and validated.

Prior consent was obtained from participants and their confidentiality was maintained. The completed questionnaire was collected and the results were tabulated.

\section{Results}

The study consisted of 250 participants and knew about CBCT as a useful diagnostic modality, out of which75.6\% ( $N=189)$ hold a MDS qualification and $64 \%(\mathrm{~N}=160)$ were females and $36 \%(\mathrm{~N}$ $=90$ ) were males.

89.6\% participants come across the term CBCT through lectures and $4.8 \%(\mathrm{~N}=12)$ through seminars, 3.6\% participants $(\mathrm{N}=$ 9) through colleagues and $2 \%(\mathrm{~N}=5)$ from internet. However only $88 \%(\mathrm{~N}=220)$ have not used CBCT for diagnostic purpose in their practice and only $12 \%(\mathrm{~N}=30)$ have used, with none taken more than 5 CBCT within a month.

All the participants felt CBCT can be used in implant dentistry, evaluation of cyst and tumors. $6 \%$ responded $(\mathrm{N}=15)$ for evaluation of impacted teeth and $12 \%(\mathrm{~N}=3)$ for orthodontic assessment. $22.4 \%(\mathrm{~N}=56)$ had no knowledge about the advantage of CBCT over other diagnostic techniques $18 \%(\mathrm{~N}=45)$ said image processing easier due to limited beam. $17.6 \%(\mathrm{~N}=44)$ think that short scanning time and data reconstruction can be performed on a personal computer. $16 \%(\mathrm{~N}=40)$ think that lower radiation dose compared to medical CT.

93.2\% of the responders were dependent on radiologist for interpretation of CBCT images, $3.6 \%$ relied on an OMR specialty and $0.8 \%(\mathrm{~N}=2)$ interpret by themselves and none of the responders said that medical professionals seek opinion on CBCT in maxillofacial region in interpretation. All the participants were interested to have hands on course on CBCT. 86.8\% $(\mathrm{N}=217)$ of the participants said that CBCT will not be commonly used as routine practice and $13.2 \%(\mathrm{~N}=33)$ said that CBCT is useful for selected dental application. 50.8\% responded that lectures on CBCT should be included in the clinical phase, $47.6 \%(\mathrm{~N}=119)$ said that it should be included in the doctoral phase, $1.6 \%(\mathrm{~N}=4)$ said there is no need of it.
$92.8 \%(\mathrm{~N}=232)$ predicted the cost of CBCT would be between $1000-1500,6 \%$ thought more than 1500 , and $12 \%$ thought less than 1000 . All the participants of the study thought there is a need for CBCT unit in their institution.

\section{Discussion}

Imaging has experienced a paradigm shift from conventional to the advanced in the recent years with the advent of numerous imaging modalities which technically converted 2-D image into 3-D life like images making interpretation and diagnosis more accurate [3]. As mentioned earlier, CBCT finds its application in almost all areas of dentistry and is one of the most widely accepted imaging modality from the past few years. Owning to its recent recognition as an imaging modality, it often found that little is known about its application and especially about interpretation of the images. Hence the present study was conducted to assess the knowledge and application of CBCT among dental professionals.

In our study we found that most of the participants were females (64\%). $75.6 \%$ hold a post graduate qualification. All the participants was aware of CBCT in dentistry similar to Yalcinkaya SE., et al. study and $89.6 \%$ came across the term CBCT through lecture similar to Balabaskaran k., et al. [4,5].

In our study $88 \%$ of the participants have not advised CBCT for their diagnostic purpose and all the participants have advised less than 5 CBCT a month. This is attributed to the cost and unavailability of CBCT at the institution. This is in accordance with Reddy., et al. and Kumburoglu., et al. on Turkish dental students which highlighted difficulties with acquiring knowledge without practical experiences, thus the lack of CBCT unit at the institution may constitute a significant factor contributing to unfamiliarity with this technology $[6,7]$.

All the participants of the study felt CBCT is a useful diagnostic tool in in dentistry which was found similar to Balabaskaran., et al. study [5]. In our study $100 \%$ of the participants responded that CBCT can be used in implant dentistry, evaluation of cyst and tumor, $6 \%$ said that it can be used for impacted teeth and $1.2 \%$ for orthodontic evaluation which was in accordance with Dolekoglu., et al. among Turkish dentists where, they were referring for CBCT for same as seen in our study and supported finding of Arnheiter., et al. study $[8,9]$. 
In another study by Yalcinkaya., et al. he found that $82.4 \%$ used CBCT for cyst and tumor, $71.6 \%$ for implant planning and $50 \%$ for trauma [4].

In our study $22.4 \%$ of participants have no idea of advantage of CBCT over other diagnostic technique and data reconstruction similar to Reddy., et al. study where they stated that it may be due to lack of practical experiences and unfamiliarity with image characteristics in image acquisition [6].
08

$86.8 \%$ of the participants responded that CBCT will not be commonly used in routine practice and $13.2 \%$ responded that it will be for selected dental applications as it is not cost effective. More than half of the participants said that lectures on CBCT should be included in clinical phase (50.8\%) and doctoral phase $(47.6 \%)$ as they start diagnosis and do treatment planning at this phase. And all the participants of the study feel necessity of having СВCT in dental institution similar to Ram Shetty., et al. Kumburglu., et al. and Reddy., et al. $[6,7,10]$. All the participants of the study were interested to attend hands on course on CBCT.

\begin{tabular}{|c|c|c|}
\hline Q. How did you come across the term CBCT & $\mathbf{N}$ & $\%$ \\
\hline Seminars & 12 & 4.8 \\
\hline Lectures & 224 & 89.6 \\
\hline Internet & 5 & 2 \\
\hline Colleagues & 9 & 3.6 \\
\hline Total & 250 & 100 \\
\hline Q. For What causes would you like to use CBCT? & $\mathbf{N}$ & $\%$ \\
\hline Orthodontic assessment & 3 & 1.2 \\
\hline Implant dentistry & 250 & 100 \\
\hline Evaluation of cysts and tumors & 250 & 100 \\
\hline Evaluation of impacted teeth & 15 & 6 \\
\hline Q. Advantage of CBCT over other diagnostic technique & $\mathbf{N}$ & $\%$ \\
\hline Lower radiation dose compared to medical CT & 40 & 16 \\
\hline Short scanning time & 44 & 17.6 \\
\hline Image processing easier due to limited beam & 45 & 18 \\
\hline Less expensive & 38 & 15.2 \\
\hline Data reconstruction can be performed on a personal computer & 44 & 17.6 \\
\hline No Idea & 56 & 22.4 \\
\hline Q. Interpretation of CBCT images & $\mathbf{N}$ & $\%$ \\
\hline Self-interpretation & 2 & 0.8 \\
\hline I rely on an OMR specialty & 9 & 3.6 \\
\hline A and B & 6 & 2.4 \\
\hline I rely on radiologist's report & 233 & 93.2 \\
\hline Total & 250 & 100 \\
\hline
\end{tabular}

Table 1 


\section{Conclusion}

The study result concluded that unfamiliarity with the use of CBCT among dental professionals may be due to insufficient curriculum and decreased practical application. So we recommend that by increasing the number of education programs, regarding the knowledge on CBCT and its application should be increased to improve dental health care practice.

\section{Bibliography}

1. Tofangchiha M., et al. “The assessment of dentists' knowledge regarding indications of cone beam computed tomography in Qazvin, Iran". Biotechnology and Health Sciences 2.1 (2015): e25815.

2. Scarfe WC and Farman AG. "What is cone-beam CT and how does it work?" Dental Clinics of North America 52.4 (2008): 707-730.

3. Alamri HM., et al. "Applications of CBCT in dental practice: A review of the literature". General Dentistry 60.5 (2012): 390400.

4. Yalcinkaya SE., et al. "Knowledge and attitudes of Turkish endodontists towards digital radiology and cone beam computed tomography". Nigerian Journal of Clinical Practice 17 (2014): 471-478.

5. Balabaskaran K and Srinivasan AL. "Awareness and attitude among dental professional towards CBCT". Journal of Dental and Medical Sciences 10.5 (2013): 55-59.

6. Lavanya R., et al. "A questionnaire cross-sectional study on application of CBCT in dental postgraduate students". Polish Journal of Radiology 81 (2016): 181.

7. Kamburoğlu1 K., et al. "Dental students' knowledge and attitudes towards cone beam computed tomography in Turkey". Dentomaxillofacial Radiology 40 (2011): 439-443.

8. Dölekoğlu S., et al. "The usage of digital radiography and cone beam computed tomography among Turkish dentists". Dentomaxillofacial Radiology 40 (2011): 379-384.
9. Arnheiter C., et al. "Trends in maxillofacial conebeam computed tomography usage". Oral Radiology 22 (2006): 80-85.

10. Shetty SR., et al. "Knowledge and attitude of dentists towards cone beam computed tomography in mangalore - a questionnaire survey". Austin Journal of Radiology 2.2 (2015): 1016.

\section{Assets from publication with us}

- Prompt Acknowledgement after receiving the article

- Thorough Double blinded peer review

- Rapid Publication

- Issue of Publication Certificate

- High visibility of your Published work

Website: www.actascientific.com/

Submit Article: www.actascientific.com/submission.php

Email us: editor@actascientific.com

Contact us: +919182824667 